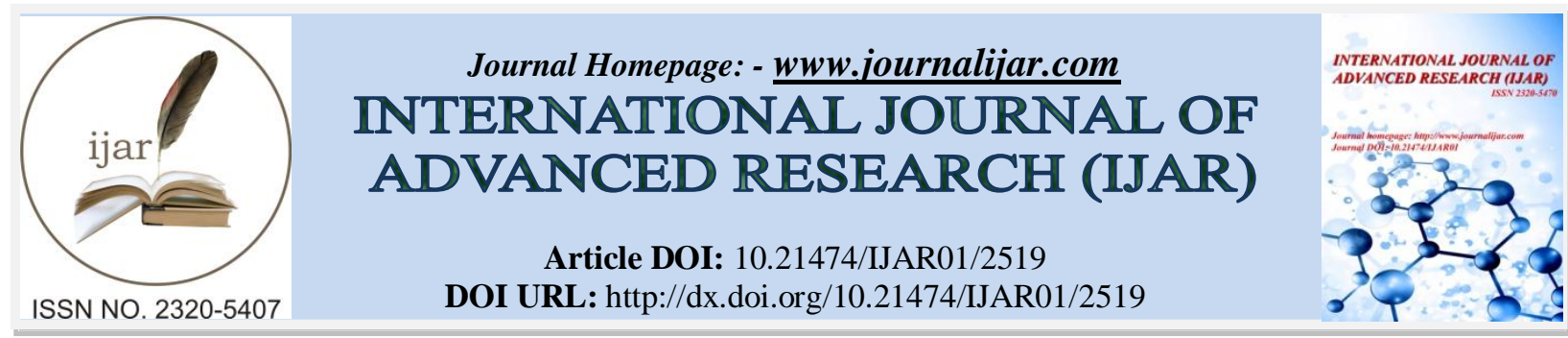

RESEARCH ARTICLE

\title{
LOGICS OF ACTORS IN WASHING MOSQUITO NETS IN COMPARISON WITH THE LAUNDRY IN VILLAGES IN IVORY COAST.
}

Doudou Dimi Theodore.

Sociologist, Health, Alassane Ouattara University, Research Center for Development.

\section{Manuscript Info}

\section{Manuscript History}

Received: 25 October 2016

Final Accepted: 23 November 2016

Published: December 2016

\section{Key words:-}

Insecticide-treated mosquito nets, LLIN, clothes, washing practices, Dabou, Ivory Coast.

\begin{abstract}
The use of long lasting insecticide-treated mosquito nets (LLINs) by households could be weakened by washing modes reducing the effectiveness of this material. This study aimed to identify LLIN washing practices in field conditions and their determinants. Such an analysis cannot be done without considering the overall logic of linen washing, because the mosquito net as the garment fits into the broad range of cloths. Hence the inclusion of washing practices of garments for comparison. Several units of two types of LLINs (Olyset net ${ }^{\circledR}$ and PermaNet $\left.{ }^{\circledR}\right)$ were distributed to women in two villages in the town of Dabou. Then, a questionnaire survey and focus groups, combined with direct observation of washing practices were conducted. The results shed light on, logics of actors to not alter the insecticide effect or the fiber of LLINs considered fragile. This shows a difference with the washing processes of certain clothing fabrics. The study reveals a combination of the concepts of clean and dirty with other criteria referring to the colour (white / dark) to the thickness of the fabric (hard / soft), etc. in washing practices.
\end{abstract}

Copy Right, IJAR, 2016. All rights reserved.

\section{Introduction:-}

Hygiene, this concept based on the beliefs, customs and the state of scientific and medical knowledge has experienced unceasing progress through the ages, before now become a universally recognized formula. This, under the impulses of scientific discoveries and health comprehensive policies (Beynier, 1998; Parent, 2011). Long attached by its etymological sense to everything that relates to the healthy and health, hygiene eventually becomes clearer to refer to all the practices and principles aimed at preserving health (Morel-Cheville, 2014). It is defined as "a set of measures to prevent infections and outbreaks of infectious diseases" (Mahmudi-Bouri, 2009). In the process of designing, the concept of hygiene has made a break with the religious perception of human nature which tends to attach to disease a sinful source and to use the prayer for healing (Thénard-Duvivier, 2012). This break visible through the work of Darwin and Pasteur is enshrined in the Treaty of the public and private hygiene by Michel Levy. This sets an operation area of hygiene as a health action affecting all aspects of life of the individual, namely:

« - Circumfusa: all the elements (water, air, etc.) that surround us;

- Ingesta: all that human consumes (food, drinks, medicines, tobacco, etc.;)

- Excreta: all that human rejects of his body (urine, sweat, etc.);

- Applicata: all that human puts on his body (clothes, make-up, tattoos);

- Percepta: all that our senses perceive;

- Gesta: the acts of diurnal life (walking, physical activities, sleep, etc.) "(Thénard-Duvivier, 2012). 
In literature, hygiene has often been approached from the point of view of the management of household waste and the improvement of the living environment in general. Personal hygiene and clothing, and especially laundry, are less discussed. These aspects are the preserve of school books and educational manuals of certain NGOs. We still have some writings on the subject. One of the works mentioned shed light on the link established between hygiene in the house and linen and body hygiene during the evolution of hygiene in France (Bloch-Raymond, 1984). Another draws up a history of the notion of hygiene: the author notes that it is a practice of ancient peoples as well as of modern peoples. He mentioned among other pioneers, Islamist doctors of the Middle Ages (Hunayn ibn Ishak, Razi, Ibn Sina, Mosheh Ben Maymon, etc.). Among these, there is the case of Mosheh Ben Maymon, physician "of the court of Saladin in the XIIth century" and author of a treaty called "Tractatus de regimine sanitatis". This treaty addresses several aspects of hygiene and provides advice on the subject. Topics covered include hygiene of clothing and personal hygiene. The author shows how hygiene has evolved from its conception of individual practice to collective practice or public hygiene, also called hygiene of the hygienist. He draws attention to the contradictions that may exist between individual and family hygienic perceptions and practices, which belong to the habitus (in the sense of Bourdieu) and the processes of collective hygiene. This contradiction creates a resistance of the actors to the change aimed at applying the rules of public hygiene (Beynier, 1998).

Purely sociological or anthropological studies mention personal hygiene. This is defined as the hygiene of the body, that is to say everything that is external to the body and accessible to the individual (skin, odours, etc.). It relates to the health of the body. Sociologists and anthropologists perceive body hygiene in two dimensions: "clean" and "dirty" or "pure" and "impure". These two notions call for collective and individual representations. Anthropology and Sociology have shown that these notions are not fixed, that they vary from one social or cultural context to another, from one social group to another, and that the social representations of these notions are themselves subjected to variations related to interactions between individuals (Douglas, 1998; Tourette-Turgis, 2014; Bloch, 2015).

The insecticide-treated mosquito net is related to two dimensions of the operating framework of hygiene defined by Lévy: Gesta, by its link with sleep, and then Applicata, as an element covering the body of the sleeper. It can even be considered as part of both domestic and family hygiene and personal hygiene (Thénard-Duvivier, 2012). This material, which is integrated into the sleeping unit within the household, is inserted in the linen of families in the same way as the cover of the sleeper, the bed sheet, the sleepwear and the clothes worn daily by the members of the household. However, does this induce a similar wash mode with clothes? This question is as important as the insecticide-treated mosquito net, is specific in that it contains insecticide. This implies a form of arbitration between hygiene issues (cleanliness of the net) and security issues (keeping a mosquito net effective). In other words, is this product not perceived by the populations as being able to decrease in intensity under the effects of washing? Cannot this perception modulate or influence the methods and frequencies of washing? In short! What are the determinants of the decision to wash the mosquito net and the choice of washing methods in comparison with those of clothing? What connection does it establish with the notions of clean and dirty / pure and impure?

These are the questions to which the present text would like to shed some light. This is in the light of the experience of women recipients of long-lasting insecticide-treated nets (LLINs) in two villages in the commune of Dabou in Côte d'Ivoire. The hypothesis that we formulate is that the MILDA / clothing comparison in terms of washing, necessarily reveals in the definition of the notion of hygiene, duality clean / dirty, pure / impure but authorizes the overcoming of this notion by the introduction of other aspects emerging from the social perceptions of the different materials mobilized. Consideration could be given to maintaining efficacy / decreasing efficacy for mosquito nets, white / dark (for both types of materials), etc.

\section{Material and Methods:- \\ Presentation of the field of study:-}

The study was carried out in the health district of Dabou in Côte d'Ivoire. The health district of Dabou is located about $45 \mathrm{~km}$ from the city of Abidjan. N'gatty and Allaba are coastal lagoon villages, adjoining.

N'gatty has a rugged relief with two important slopes. The eastern slope is bounded by the Ebrie lagoon, and the western slope by a banana plantation. There is an absence of pools of water inside the village. But, its borders are conducive to the development of mosquitoes. No positive mosquito bed was observed on the lagoon margin. However, the road along the banana plantation is littered with borrowings truck tire. These borrowings represent the 
bulk of the positive breeding sites in the village. The population of this village is mainly composed of indigenous Adjoukrou.

Unlike N'Gatty, Allaba is housed in a basin with a sandy soil. This promotes the infiltration of water after rain. It was therefore difficult to find puddles of water. Nevertheless, the population complains about the nuisance of mosquitoes. Most of them are Beninese living of fishing. The natives are Ahizi.

\section{Mosquito nets distribution and survey about the washing practices:-}

A total of 680 mosquito nets were distributed to women in the villages of N'Gatty and Allaba, including 580 units of Olyset net ${ }^{\circledR}$ and 100 of Permanet ${ }^{\circledR}$. The difference between these numbers can be explained by the variety of stocks available to the research team.

At the 6th month of LLIN use, a questionnaire survey was conducted among all the beneficiaries' women. The purpose of this survey was to identify the practices used by these women to wash their insecticide-treated mosquito nets. There were 468 Olyset net ${ }^{\circledR}$ beneficiaries who were actually present during the survey period, ie a completion rate of $80.67 \%$. As for Permanet ${ }^{\circledR}, 64$ out of 100 beneficiaries were present. Either an achievement rate of $64 \%$.

Focus groups were also carried out in order to identify, on the one hand, women's motivations for the choices made and, on the other, their washing practices of clothes. In each village, two groups of 12 participants, one of whom are beneficiaries of Olyset net ${ }^{\circledR}$ and the other of women beneficiaries of Permanet ${ }^{\circledR}$, have been organized. In addition, a mixed group of 6 beneficiaries of Permanet ${ }^{\circledR}$ and as many women for Olyset net ${ }^{\circledR}$ was formed. In each village 3 discussion groups and 6 in total were held. The language used in the focus groups was the French generally understood and more or less spoken by the women of the two villages. An interpreter was nevertheless present for women who preferred to express themselves in their dialect. It was either the adjoukrou, the fon or the ahizi. The study of washing practices was limited to focus groups and direct observation of laundry scenes in about 20 households in both villages.

\section{Different types of LLIN distributed:-}

See the note below (Skovmand, 2008):

The Olyset Net ${ }^{\circledR}$ mosquito net (Sumitomo) was the first WHO-recommended long lasting impregnated polyethylene mosquito net. In practice, this mosquito net can be used and washed frequently while remaining effective for 5 years. However, some studies show that, where there are resistances, the large width of the mesh of the tulle allows the mosquito to penetrate and sting, which cancels the individual protection. Nevertheless, many mosquitoes may still receive enough insecticide after they have bitten and eventually die, but this effect is notable unless more than $60 \%$ of the houses are equipped with impregnated mosquito nets.

The Permanet ${ }^{\circledR}$ mosquito net was developed by Intelligent Insect Control for Vestergaard Frandsen in 1999-2002. This second mosquito net is made of polyester, treated exactly like mosquito nets soaked in insecticide, but the treatment is carried out in the factory at a higher temperature which makes the impregnation much more resistant. Individual protection is good as long as the mosquito net is intact because the mesh is narrow enough to prevent mosquitoes from passing through the mesh.

Olyset Net and Parmanet LLINs distributed to populations of study sites are different at several points (large / fine mesh, fiber material: polyethylene / polyester, insecticide: permethrin / deltamethrin). However, both types of mosquito net were of identical blue colour, the only colour available for the research project.

\section{Instructions given to women During Distribution:-}

No special instructions were given to the beneficiaries regarding the washing process of the mosquito nets. Except that, these mosquito nets contain insecticide. This last aspect cannot go unnoticed by the beneficiaries given the perfume emitted by each impregnated mosquito net. The objective was, as best as possible, not to influence the washing methods specific to the beneficiaries, but rather to highlight them. They were advised to install their mosquito net and use it. Young village volunteers, selected by the customary authorities themselves, were responsible for helping households that did not master the technique to install the mosquito net. They were also told that they were long-lasting insecticide-treated mosquito nets. On the other hand, we told the women that we would come back and inquire about their opinions about the nets distributed. 


\section{Data processing and Analysis:-}

The quantitative data were entered using the Excel 2000 software and transferred to the STATA software for processing and analysis. This part of the study was limited to a descriptive statistical analysis.

The qualitative data from the focus groups were entered using the Word 2000 software and transferred to the NVIVO qualitative data processing and analysis software.

For the interpretation of the results, a theory belonging to the family of theories of social action was mobilized. This is the methodological individualism of Raymond Boudon. This theory recommends taking into account the "intentional and strategic" dimension of the actors (Ferréol et al., 2002), (Boudon and Bourricaud, 1982, in De Singly, 1985). In other words, methodological individualism will enable us to highlight the logics behind the individual actions of women. The main emphasis will be on one of its basic principles, namely the actor's rationality (Benoit, undated). This one admits that individuals have good reasons to act as they do. Thus, we will work to reconstruct the motivations of the choices made by women in the washing of LLINs.

The practices examined herein are: washing frequency, soaking, soaking time, soaking soap, washing water, washing soap, washing mode, amount of wash water, the amount of rinse water, the drying place and the drying position.

\section{Results:-}

The clean and the dirty through the washing frequency:-

A total of $66.5 \%$ of Olyset net ${ }^{\circledR}$ had not been washed; only $33.5 \%$ were washed. Conversely, for Permanet ${ }^{\circledR}$, it is noted that after 6 months of use a large part of the nets, almost three quarters had been washed (74.1\%).

Most Olyset net ${ }^{\circledR}$ washed (63.7\%) were washed bi-monthly (once every two months); $31.8 \%$ were washed monthly, and only $4.4 \%$ were at a frequency of three months or more. There is a difference with the Permanet ${ }^{\circledR}$ mosquito net. Indeed, the frequency most noted is that of three months or more $(42.8 \%) ; 30.9 \%$ of LLINs Permanet ${ }^{\circledR}$ were washed monthly and $26.1 \%$ every two months.

It is clear from the focus groups that the determination of the frequency of washing is linked to the perception of the level of soiling reached by the net at a given moment of its use. The woman sometimes fixes a time not to exceed, corresponding to the limit of the tolerable in terms of dirt.

"As at that time it's dirty, that's why I wash." K.V, 33, a shopkeeper.

"For me it's been three months and I wash, because when it's three months, it's not good, it becomes another colour (changes colour) so it's dirty; It must not exceed three months ". A. H., 28 years old, cultivator.

Some women feel that the mosquito net does not get dirty easily and therefore does not need to be washed frequently.

"I'm waiting three months because the mosquito net does not get dirty." A. D, 39, housewife.

The frequency of washing is also related to the fact that other women, who do not often wash their mosquito net, hope to keep it in good condition and at the same time maintain the insecticidal effect.

"If you wash too much that mosquito net it will spoil (damage the fiber) and the product (the insecticide) will end in it" G. V., 24, cultivator.

This allusion to the risk of damaging the mosquito net is what justifies (as mentioned above) that Permanet ${ }^{\circledR}$ mosquito nets are less frequently washed than Olyset net ${ }^{\circledR}$. Olyset net ${ }^{\circledR}$ fiber is made of polyethylene and is perceived by women as stronger than Permanet ${ }^{\circledR}$, which is made of lightweight polyester. 


\section{Soaking LLIN against dirt deeply buried:-}

Just over half of the washed Olyset nets were first dipped (57.8\%). $42.1 \%$ were not soaked. On the other hand, with Permanet ${ }^{\circledR}$ the most pronounced trend was non-soaking $(56.2 \%)$, less than half of the beneficiaries encountered dipped their LLIN Permanet ${ }^{\circledR}(43.7 \%)$.

The most commonly used pattern in focus groups by women engaged in soaking is that, it is easier to remove the dirt from the mosquito more quickly and deeply. So, dipping is for these women, the ideal way to clean up the blood stains left by mosquitoes, dust, as well as smokes from the kitchen and removes odours from children's urine. Moreover, the soaking, because of the relatively prolonged presence of the mosquito net in the soapy water, would provide a good perfume to the latter and would make it possible to kill the microbes that it contains.

Women who do not dip their mosquito net before washing said, they do not wait until the mosquito net becomes very dirty before washing it, or that the fabric is easy to wash. Other women noted the lack of time and the many occupations they face during the day as reasons for their inability to soak their mosquito nets.

In most cases, dipping of Olyset net ${ }^{\circledR}$ lasted less than 30 minutes (64\%). Approximately one-quarter of these soaked LLINs were for a period of one hour to more than one hour $(25.3 \%)$. For a small proportion, the soaking time was from 30 minutes to less than one hour. Unlike Olyset, just under half of the Permanet ${ }^{\circledR}$ soaked were soaked for 30 minutes to less than an hour (47.6\%), when $28.5 \%$ were soaked for less of 30 minutes and $23.8 \%$ for at least an hour of time.

Almost all Olyset net ${ }^{\circledR}$ soaked were soaked with industrial soap powder (91.4\%); A very small proportion was soaked with Marseille soap (7.1\%). Permanet ${ }^{\circledR}$ LLINs were also soaked mainly with industrial soap powder (60.4\%); But $23.2 \%$ were soaked in soap water obtained with Marseille soap, and 16.2\% with soap made locally (usually solid soap called kabakrou, and sometimes liquid soap).

Focus group data reveal that, for soaking nets, women generally use powdered industrial soap because they believe it is effective in removing stains while facilitating washing.

"I dip with Omo, washing with Omo is easy, just a little and it's clean." RW, 40, housewife.

Moreover, it would eliminate the microbes and give a pleasant perfume to the mosquito net.

Here a triad emerges in reference to dirty and clean; dirty as a carrier of germs or microbes; dirty as a source of bad odours and dirty as a task or visible mark. On the contrary, there is the clean as the absence of microbes, the clean as the provider of pleasant odours and the clean as the absence of spots.

The washing soap of LLIN a revealing factor of the clean as a pleasant odour:-

Much of the Olyset net ${ }^{\circledR}$ washed, were with Marseille soap (44\%); $39.5 \%$ were washed with industrial soap powder, and $16.4 \%$ with traditional soap or manufactured locally.

In contrast, washing of Permanet ${ }^{\circledR}$ LLINs was mainly done with powdered soap (60.4\%); $23.2 \%$ were washed with Marseille soap and $16.2 \%$ with traditional soap.

Focus groups confirm that women use various types of soap to wash the mosquito net, but powdered soap remains highly prized. The women use it either by habit acquired with washing other types of linen, or because this soap would produce a lot of foam, would remove dirt, kill microbes or give a pleasant perfume to the mosquito net. These women are used to soaking the mosquito net with powdered soap and using the same soapy water obtained to wash it.

"I no longer use soap to wash because when you soak the mosquito net in Omo, it foams a lot already so I do not need to take soap." L. B., 33, a trader.

The second type of soap used to wash the mosquito net is Marseille soap. Women who use it have the same reasons as users of powdered soap. But they add that Marseille soap is less harmful and allows to keep the insecticide longer or to prevent the mosquito net from tearing. 
A few women take liquid soap to wash their mosquito net. The essential reason they evoke is the pleasant odour of this type of soap.

Moreover, it should be mentioned that some women do not remain loyal to a specific soap; they choose the type of washing soap according to their current financial situation. Thus, they use Marseille soap or powdered soap when they have enough resources, and resort to traditional soap "kabakrou" during difficult times.

Specifically, there are variations according to the group of women surveyed. The use of powdered soap is very widespread among indigenous women Adjoukrou and Ahizi. As for the Beninese foreigners, they mainly use either Marseille soap or handmade soaps (kabakrou, black soap).

Olyset net ${ }^{\circledR}$ were mostly washed with plenty of water $(57.8 \%)$; $30.8 \%$ were washed with an average amount of water, and only $11.2 \%$ with little water. The same trends are observed in LLIN Permanet ${ }^{\circledR}$. The vast majority of women $(65.1 \%)$ use a lot of water to wash them; $18.6 \%$ of LLINs Permanet ${ }^{\circledR}$ were washed with an average amount of water and $16.3 \%$ were washed with little water.

Qualitative data confirm that the most common practice is to use a significant amount of water to wash the mosquito net. Women who practice this, either believe that their mosquito net is large, or that it takes a lot of water to ensure better cleanliness of the mosquito net.

Slightly more than half of the Olyset net ${ }^{\circledR}$ were washed with water from the tap (54.2\%), washing of the others with water from wells $(44,2 \%)$. On the other hand, for water sources used for washing LLINs Permanet ${ }^{\circledR}$, water from wells served in $61.1 \%$ of cases and tap water in $38.1 \%$ of cases.

In reality, the use is made of well water or tap water depending on the villages. In N'gatty, a village with hydraulic infrastructure, households usually use tap water. In contrast, in Allaba where there is no drinking water supply, women use water from wells. The respondents say they do not use the water in the lagoon because it is not suitable for washing the mosquito net. Because not only would this water not produce enough foam but it would contain a lot of salt.

More than half $(60.1 \%)$ of washed Olyset net were rinsed with a large amount of water; $27 \%$ with an average amount of water, and $12.7 \%$ with little water. For LLIN Permanet ${ }^{\circledR}$, approximately three-quarters $(74.4 \%)$ were rinsed with a large amount of water, $16.3 \%$ with average water, and $9.3 \%$ in a small amount of water.

Concerning the reasons for the use of such amounts of rinse water, focus groups reveal that women who rinse with a lot of water do so in order to remove the large amount of soap foam, contained in the mosquito net. Another reason cited by women is that the fabrics of mosquito nets produce a lot of foam.

"I take a lot of water to rinse because the mosquito net foams a lot, especially when you soak, it takes a lot of water so that the foam can finish." A.M., 23 years old, housewife.

Moreover, the use of a large quantity of rinsing water is part of a logic aimed at ensuring better cleanliness of the mosquito net after washing.

"I use a lot of water because, it makes it cleaner." B.P., 27 years old, cultivator.

\section{The soft or fragile and the caution in the washing and drying modes:-}

Almost all Olyset net ${ }^{\circledR}$ were hand-washed (94\%), compared with only $5.9 \%$ washed by other means (these methods consisted of not rubbing the mosquito net, but shake simply after soaking, in order to reduce the risk of lowering the insecticide effect). For LLIN Permanet巴, all of them were hand washed (100\%).

Focus groups attest that women wash their mosquito nets mainly by hand, so they say to avoid cracking. According to them, the laundry wood is not suitable for washing the fabrics of mosquito nets, these being light and fragile.

"I wash with the hand because it is soft (the fabric) and then when you wash with the hand it becomes clean so it is not worth taking the wood". L.Y., 42 years old, grower. 
The majority of Olyset net washed were dried in the sun $(92.5 \%)$; a very small proportion was dried in the shade (7.4\%). This is the same for LLIN Permanet ${ }^{\circ}: 95.3 \%$ were dried in the sun and only $4.7 \%$ in the shade.

The focus groups confirm the two methods of drying the mosquito net: drying in the sun and drying in the shade. The most common mode is sun drying. It is justified by the women's desire to dry the mosquito net quickly.

Moreover, some women justify drying the mosquito net in the sun by a habit of drying clothes on ropes exposed to the sun.

As for the drying in the shade, it is justified by the concern of some women to retain the smoothness of the fabric of the mosquito net. They believe that the sun tends to harden. Another reason for drying in the shade is that the mosquito net would not take enough time to dry or that the ropes used are in the shade.

Most Olyset net® LLINs were dried vertically (97.7\%), with the exception of a few drying (2.2\%). All LLIN Permanet巴 $(100 \%)$ were dried vertically.

\section{White and dark, for child and adult, hard and soft in washing clothes:-}

The women encountered establish a categorization of clothing according to the age of the wearer, the specificity of the fabric and its colour. Indeed, when it comes to the clothes of children under 15 years old, they are generally soaked in water using industrial soap powder. The argument put forward by mothers is that children play a lot in the dust, and their clothes are generally dirtier than those of adults. Adult jeans trousers, especially the father of the family, also suffer the same fate because of the heaviness of the fabric. White clothes are sometimes soaked with detergent in addition to powdered soap.

They generally claim to wash the family's clothes on average once a week. However, when it comes to an baby, his clothes are washed daily.

Washing water is the water that women have at disposal: well water for Allaba and tap water for those of N'Gatty. They claim to use a very large amount of water to wash clothes. They support doing as much at the time of rinsing, to be sure to have removed all the impurities from the clothes.

The soap generally used, when it comes to children's clothes and hard fabrics, is handmade. It is called "kabakrou" (stone in a local dialect called Malinke), because "solid as a stone" (photo 1). The women believe that with its strong dosage of potash, it is able to remove all the impurities and kill the microbes. For other types of linen, women prefer to use Marseille soap, especially for its perfume.

Clothes are hand-washed. But, those who are considered very dirty (especially children's clothes) or hard, are washed using a washing board (photo 2). This permits faster rubbing.

Drying is generally done vertically on clothes lines installed by each household for this purpose. However, when the layout of the domestic space allows, some women put the clothes horizontally, out of wooden shelves. Clothes are exposed to sunlight.

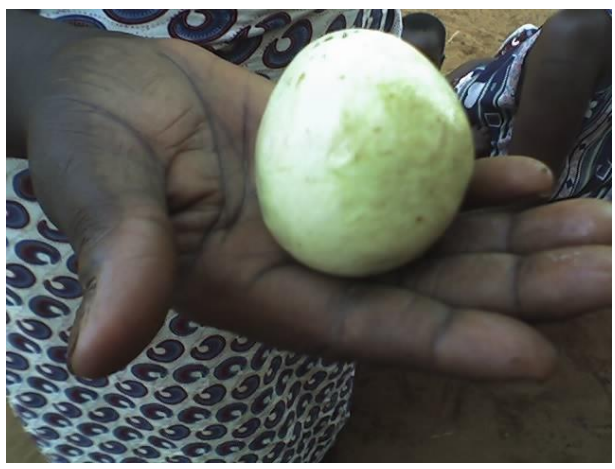

Photo n'1:- A traditional soap " Kabakrou " held in the hand by a woman from the village of Allaba, (Dabou, Ivory Coast) 
Source:- Sociological component of the MIM-TDR project / A50066

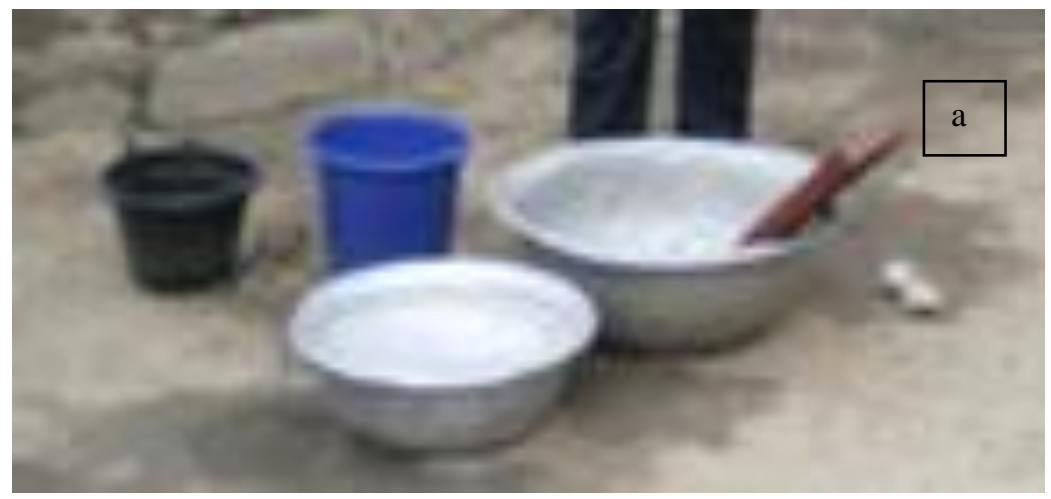

Photo n'2:- A washing board (a) among the arsenal of washing equipment in a household in the village of N'Gatty (Dabou, Côte d'Ivoire).

Source:- Socio-anthropological component of the MIM-TDR project / A50066

\section{Discussion:-}

It should be noted that, in view of the results presented, the reconstruction of the social logic of the users regarding the washing of their LLIN is based on the indicators of soiling that emerge from the discourse of the beneficiary women. These reveal three orders of dirty and clean. One is sight-related and is linked to tarnishing the colour of the LLIN, especially as a result of blood spots left by mosquitoes, dust or in some cases smoke from the kitchen. The other relates to smell, and refers in particular to the odours of children's urine. In this case, the decision to wash the LLIN is made following an observation exercise performed by the mother. Note that the smoke evoked here refers to the proximity of the kitchen (usually external to the dwelling) with regard to a bedroom window. The third category is related to the time of use, the user setting threshold duration of use not to be exceeded for washing, usually 3 months for the cases reported by this study. Let us note with Denèfle (1989) that the question concerning the decision to wash the clothes appears very delicate, from the moment when, according to the author, touching the practices relating to clean and dirty leads to questioning the intimacy of people.

Concerning the washing practices themselves, we note a concern among the women of our study, not to damage the fibers of the LLIN and not to cause the loss of the insecticide. This result in a relatively low washing frequency compared to that of clothes, as well as the choice of soaps supposed not to have a corrosive effect (not detergent use) and the unique use of the hands, rather than hard objects to wash the LLIN. The fear of losing the insecticidal effect is also mentioned by Atkinson et al. (2009), but these authors also mention the non-availability of water as a lowfrequency washing factor of LLINs. The hygienist thesis is mentioned with regard to soaking, when women allude to the fight against microbes and to maintain a good fragrance at LLIN. Here we have a concern for prevention, resorting to soaking to prevent the microbes in the dirt from causing damage to the body and to health. Welzer-Lang and Filiod (1993) interested in hygiene practices in the domestic space also mentioned the concept of prevention. In an analysis based on the notions of clean / dirty, tidy / disorder, they raise a concern for prevention in women engaged in the cleaning of domestic space.

Washing practices highlight differences and similarities between clothing and LLIN. Thus, as regards soaking, in both cases (garment and impregnated mosquito net) it is a common practice. However, the decision to wash is subject to conditions for clothing (white colour, high degree of dirt, heaviness of the fabric). As far as the LLINs of the present study are concerned, the white colour is not evoked, certainly because the two types distributed were identical in colour (blue).

There is also similarity in reference to the degree of soiling as justification for soaking. However, it is at the level of the heaviness of the fabric that a great difference is found. Indeed, while heavy fabric garments are more likely to be soaked, mosquito nets are soaked because they have a light fabric. Here, the delicacy of the fabric causes the women to opt for soaking, in order to facilitate the removal of the dirt without the need to rub too much. In this way, they hope to avoid the effects of excessive friction of the mosquito net (cracking, loss of insecticide effect). Whether it is LLIN or clothes, it is either tap water or well water (N'Gatty) or well water only (Allaba) that is used. The water of the lagoon is avoided by women who feel that the salt it contains can damage clothes just like the mosquito net. 
Similarly, the drying mode does not vary considerably. Both LLINs and clothing are usually dried vertically on a rope. On the other hand, as regards the washing method, the washboard used in some cases for washing clothes is not used for impregnated mosquito nets. The same concern not to damage the mosquito net, whose fabric is perceived as fragile, is advanced by women. Moreover, and for the same reason, with regard to the frequency of washing, it is noted that the mosquito nets are washed less often than the clothes. This attitude of women to avoid thorough washing methods is in accordance with the prescription of Atieli et al. (2010). These authors have tested the efficacy of four LLIN models in field conditions and show that the WHOPES standards for washing LLINs at the Laboratory are out of phase with the field conditions. They note that community washing practices are harsher and affect the effectiveness of the material. They recommend sensitizing users to the use of a softer washing mode. The authors also encourage drying in the vertical, but in the shade. The vertical position is respected by our target populations, but the general trend in this study is exposure to sunlight. Kayedi et al. (2008) following entomological tests carried out on sun-dried or sun-dried MILDA clusters, recognize that it is preferable to dry LLINs in the shade. However, they indicate that exposure of LLIN to sunlight is advisable provided that it lasts no longer than 3 hours. Curtis (2003), based on the results of various authors, was already cautious about the expected efficacy of LLINs (5 or even 7 years) (Hougard et al., 2003). Some studies showed decreased efficacy in both re-impregnable mosquito nets and LLINs after a small number of washings, others gave an advantage to the latter in the first, while in others both types have a relatively long duration of effectiveness. The results of the entomology team of this research project go in the same direction. The amount of Permethrin present in the OlysetNet ${ }^{\circledR}$ samples tested by the entomologists at the Laboratory prior to the distribution of LLINs in the two villages was $1168.81 \mathrm{mg} / \mathrm{m}^{2}$. This amount dropped to $577.25 \mathrm{mg} / \mathrm{m}^{2}$ after 6 months of use in the communities. This corresponds to a decrease of $49.44 \%$, relative to the initial dosage. As for LLIN Permanet, the initial dose of deltamethrin found in laboratory samples (prior to distribution) was $43 \mathrm{mg} / \mathrm{m}^{2}$. The one obtained after 6 months of use was $15.3 \mathrm{mg} / \mathrm{m} \mathrm{2}$. This makes a decrease of $35.25 \%$ of the insecticide dose after six months of use in households. Regarding the effectiveness of these two LLINs, the team's entomologists concluded that they lost their effectiveness after six months of use under field conditions, with a mortality rate of $35.41 \%$ for OlysetNet ${ }^{\circledR}$ compared with $100 \%$ before distribution (T0), and 35.85\% for PermaNet ${ }^{\circledR}$ instead of $99.65 \%$ before distribution (T0) (IPR / INSP, 2011, Djakaridia, 2013).

Regarding the washing of the garments considered separately, the study revealed a variation in washing practices according to the type of garment. A similar differentiation is mentioned by Fischer (2013). The author is interested in the different categories of linen in hospitals from the example of civil hospitals in Colmar. It reveals a distinction in the circuit and cleaning practices, depending on whether it is "flat linen" or hotel linen made up of bibs, blankets, sheets, towels and other types of linen. Bloch-Raymond (1984) describes the gradual changes brought by the washing machine to the habits of the housewife in France. The practices of these women show a difference of washing between "light", "intimate" or "delicate" linen, which is washed by hand and the less light laundry that has been machine-washed. As for Riffault (1980), he establishes a very interesting nuance between washing machine and laundry. The first uses softness, while the second is an action involving chemicals to restore the purity or whiteness of the linen.

\section{Conclusion:-}

In the end, the washing practices of LLINs, mobilized by women in the villages of N'Gatty and Allaba - two villages where water availability is not a problem - highlight obstacles linked to a perception that they have of these materials. These perceptions serve as a basis for the social logics that guide the decision to wash and wash practices among beneficiaries. Women consider LLINs to be fragile from the point of view of their fiber, judged to be flexible in comparison with the fabric of clothing, and the presence of an insecticide which they consider to be capable of lowering their effectiveness under the effect of rough friction. This means that the laundry is excluded from the washing process (unlike clothing), and the net is less often washed than clothes. It is preferred to soak it in water with powdered soap and then rub it lightly against the hands. This view of women appears to be beneficial in terms of maintaining the duration of the insecticidal effect, based on studies that have shown a rapid loss of efficacy of certain LLINs and insecticide-treated nets in general, after a few washes. However, additional studies are needed to account for the relationship between this attitude of women regarding washing practices and the lifetime of LLINs, but also to ascertain whether soaking and soap powder to do so, do not in fact lead to unintended effects. In other words, does soaking, as desired by women, preserve the effectiveness of LLIN? On the other hand, the comparison of the washing methods of different materials such as mosquito nets and clothing appears as a heuristic field from the sociological point of view. We note not only a variation of the logics of actors in the decision to wash as well as 
in the choice of washing processes from one type of material (mosquito net) to another (garment), but also the need for coupling clean / dirty, pure / impure concepts with those especially of hard / soft, white / dark.

\section{Acknowledgment:-}

This research was carried out within the framework of the Ivorian component of the project "Impact of washing practices on long lasting insecticide impregnated mosquito nets under field conditions in Benin, Burkina Faso and Cote d'Ivoire", financed by the WHO through The MIM (Multilateral Initiative on Malaria), of which I was in charge of the sociological aspect in Ivory Coast.

\section{Bibliographical References:-}

1. Atieli F., Munga S., Ofulla A., Vulule John, 2010: Wash durability and optimal drying regimen of four brands of long-lasting insecticide-treated nets after repeated washing under tropical conditions. », Malaria Journal, 9, 248.

2. Atkinson J-A., Bobogare A., Fitzgerald L., Boaz L., Appleyard B., Toaliu H., Vallely A., 2009: A qualitative study on the acceptability and preference of three types of long-lasting insecticide-treated bed nets in Solomon Islands: implications for malaria elimination, Malaria Journal, 8,119.

3. Benoit, F.M., (non daté): Les logiques d'action individuelles. http://www. http://dea128fc.free.fr/CoursB/B3_EPI/doc\%20benoit-Float/Les\%20logiques\%20d'actions\%20individuelles.htm (consulté le 03/06/14).

4. Beynier D., 1998: Entre hygiène savante et hygiène quotidienne : une explication à la résistance au changement, Actes de la journée de réflexion sur l'hygiène hospitalière, Caen.

5. Boudon R., Bourricaud, 2002: L'individualisme méthodologique, in De Singly (dir.), 1995-Les nouvelles sociologies, constructions de la réalité sociale, Editions Nathan, Paris, 14-15.

6. Bloch-Raymond A., 1984: Bateaux-lavoirs, buanderies et blanchisseries. Des relations entre espaces publics, espaces privés. Revue des Sciences Sociales de la France de l'Est Strasbourg, (13-13), 3-21.

7. Curtis C. F., 2003: Improving and scaling up vector control, the impact of insecticide resistance and possible means of resistance management, Report of the Scientific Working Group on Malaria, Annex 7, WHO, Geneva.

8. Denèfle S. 2007: "' Tant qu'il y aura du linge à laver... ', Terrain [En ligne], 12 | avril 1989, mis en ligne le 18 juillet 2007, consulté le 18 septembre 2015. URL : http://terrain.revues.org/3329 ; DOI : 10.4000/terrain.3329

9. Djakaridia F. 2013: Transmission du paludisme et durée de l'efficacité insecticide des moustiquaires imprégnées à longue durée d'action (MILDAA) dans les conditions d'utilisation de terrain en milieux côtier lagunaire et Sud forestier de la Côte d'Ivoire : Cas de Dabou et de Tiassalé. Thèse Unique pour le doctorat de l’Université Félix Houphoët Boigny, Abidjan.

10. Ferréol G., Cauche P., Duprez J.M., Gadrey N., Simon M., 2002 [1ère ed. 1991]: Dictionnaire de Sociologie, Paris, Armand colin.

11. Fischer M., 2013: La fonction linge aux hôpitaux civils de Colmar : formalisation et mise en place d'outils de suivi. Mémoire de l'Ecole des Hautes Etudes en Santé Publique, 56 p.

12. Hougard J-M., Corbel V., Darriet F.: 2003. Moustiquaires de choc, Sciences au Sud, (22), 10.

13. IPR/INSP, 2011: Projet MIM A50066 : Rapport final de l'équipe de Côte d'Ivoire, Abidjan.

14. Kayedi M. H., Lines J., Haghdoosta A. A., Vatandoost H., Rassi Y., Khamisabadi K, 2008. Evaluation of the effects of repeated hand washing, sunlight, smoke and dirt on the persistence of deltamethrin on insecticidetreated nets, Transactions of the Royal Society of Tropical Medicine and Hygiene, (102), 811-816.

15. Mahmoudi-Bouri, 2009: Genre et organisation sociale du travail domestique : pratiques et représentations : exemple pour deux catégories les femmes actives et les femmes au foyer, Mémoire de fin d'études pour l'obtention du Diplôme de magistère, Université d'Oran-Es Senia, faculté des sciences sociales, 151 p.

16. Mary Douglas, 1998: "'La pureté du corps ', Terrain [En ligne], 31 | septembre 1998, mis en ligne le 21 juillet 2005, consulté le 12 septembre 2016. URL : http://terrain.revues.org/3131 ; DOI : 10.4000/terrain.3131

17. Bloch M., 2015. " Mary Douglas et les cacahuètes ", Terrain [En ligne], 65 | septembre 2015, mis en ligne le 15 septembre 2015, consulté le 29 juin 2016. URL : http://terrain.revues.org/15873 ; DOI : 10.4000/terrain. 15873

18. Morel-Cheville, (non daté) : La professionnalisation du discours pour intervenir autour du thème délicat de l'hygiène corporelle. [cited 2014 Jun 5]; Available from: http://shs-app.univrouen.fr/civiic/memoires_masterICF/textes/T_MOREL-CHEVILLET.pdf 
19. Parent C., 2011: L'hygiène personnelle des membres de l'élite administrative française au XVIIIe siècle : Étude des objets de l'hygiène contenus dans les latrines ouest du second palais de l'intendant à Québec, CeEt (30), 1719-1759.

20. Riffault, M. C., 1980: De Chaptal à la Mère Denis: histoire de l'entretien du linge domestique in Machines au foyer. Culture Technique anc Technique et Culture Neuilly-sur-Seine, (3), 257-263.

21. Skovmand O., 2008: Prévention du paludisme par la lutte antivectorielle, http://www.devsante.org/basedocumentaire/sante-publique-prevention/prevention-du-paludisme-par-la-lutte-antivectorielle, Développement et Santé $n^{\circ} 189$ (consulté le : 02/06/14).

22. Thénard-Duvivier (SD), 2012: Hygiène, Santé et Protection sociale. De la fin du XVIIème siècle à nos jours, Editions Ellipses, Paris.

23. Tourette-Turgis C., (non daté): La professionnalisation du discours pour intervenir autour du thème délicat de l'hygiène corporelle. [cited 2014 Jun 5]; Available from: http://shs-app.univrouen.fr/civiic/memoires_masterICF/textes/T_MOREL-CHEVILLET.pdf

24. Welzer-Lang, D., Filiod, J. P., 1993: Les hommes à l'épreuve du désordre. Approche anthropologique de la sexuation de l'espace domestique. Dialogue. Recherches cliniques et sociologiques sur le couple et la famille, 121, 82-94. 